\title{
Impact of Chemotherapy-induced Peripheral Neuropathy on Quality of Life in Patients with Advanced Lung Cancer Receiving Platinum-based Chemotherapy
}

\section{Hsing-Wei Hung}

Linkou Chang Gung Memorial Hospital: Chang Gung Memorial Hospital

Chien-Ying Liu

Linkou Chang Gung Memorial Hospital: Chang Gung Memorial Hospital

Hsiu-Fang Chen

Chang Gung University of Science and Technology

Shu-Ching Chen ( $\nabla$ shuching@gw.cgust.edu.tw)

Chang Gung University of Science and Technology https://orcid.org/0000-0002-7921-1964

\section{Original Article}

Keywords: lung cancer, chemotherapy, cisplatin, carboplatin, chemotherapy-induced peripheral neuropathy, quality of life

Posted Date: February 17th, 2021

DOI: https://doi.org/10.21203/rs.3.rs-200944/v1

License: (c) (1) This work is licensed under a Creative Commons Attribution 4.0 International License.

Read Full License 


\section{Abstract}

Purpose: Chemotherapy-induced peripheral neuropathy (CIPN) is a common adverse event of cancer treatment that may affect quality of life (QoL). The purposes of this study were to: assess the levels of CIPN, depression, general QoL, and CIPN-related QoL; and identify the factors related to CIPN-related QoL and general QoL in patients with advanced lung cancer (LC) receiving platinum-based chemotherapy.

Methods: This cross-sectional study examined patients with advanced LC who received platinum-based chemotherapy from the thoracic oncology inpatient wards of a medical center in northern Taiwan. Structured questionnaires were used to measure patients' CIPN, depression, general QoL, and CIPNrelated QoL.

Results: Of the 93 patients with advanced LC studied, 53.8\% and $47.3 \%$ reported CIPN-sensory impairment and CIPN-motor impairment, respectively. The most common CIPN symptoms were difficulty getting or maintaining an erection and difficulty in climbing stairs or getting up out of a chair. Poor CIPNrelated QoL was associated with more CIPN-sensory and more CIPN-motor impairment. Poor general QoL was associated with a higher level of depression, more CIPN-sensory impairment, and a higher cumulative dose of chemotherapy.

Conclusion: More than half of LC patients report impairment related to CIPN. This finding highlights the importance of treating these symptoms which significantly impair QoL. A holistic approach - including patient health education, dietary adjustment, nutritional supplements, aerobic exercise, and balance training - is needed to relieve the distressful peripheral neurological symptoms and emotional distress of CIPN during and after treatment for advanced LC.

\section{Introduction}

Lung cancer (LC) is the most common cancer worldwide, with an estimated 2.1 million new cases and approximately 1.76 million deaths expected annually [1]. In Taiwan, some 12,000 new LC cases are reported per year [2]. About 75\% of patients are diagnosed at an advanced stage, and chemotherapy is the major treatment modality [3]. Chemotherapy-induced peripheral neuropathy (CIPN) is a common side effect of several classes of chemotherapy agents, including platinum-based agents, such as cisplatin and carboplatin [4]. Approximately $70-100 \%$ of patients treated with platinum-based antineoplastics report CIPN [4], which may develop 1-2 weeks after initiating treatment, persist for several months after completing treatment, and depend on the cumulative dose exposure [5].

CIPN refers to motor, sensory, and autonomic neurons dysfunction, which presents as peripheral neuropathic signs and symptoms, and includes sensory damage. The predominant symptoms of CIPN are paresthesia, numbness and tingling, dulled sensations in the peripheral nerves, burning and shooting pain, or electric shock-like pain [3,6]; motor damage can be manifested as weakness, gait and balance disturbance, and difficulty with fine motor skills [6]. Autonomic damage dysfunction presents as constipation, orthostatic hypotension, and urinary incontinence [7]. The neuropathy symptoms may 
cause dose reduction [8], refusal to continue treatment [9], psychological distress [10], neurological impairment [11], and reduced quality of life (QoL) $[12,13]$.

Although previous studies have explored these issues, most research has focused on patients with colorectal cancer [14-16], breast cancer [17], or those in Western countries [18-20]; or on other chemotherapy regimens such as taxane [18,19], paclitaxel $[19,20]$, or carboplatin $[19,20]$. Clinical observation indicates that LC patients treated with platinum-based regimens report CIPN-related symptoms that affect daily function and QoL, and insufficient attention has been devoted to this important topic. Therefore, the purposes of this study were to (1) examine the levels of CIPN, depression, general QoL, and CIPN-related QoL; and (2) identify the factors associated with CIPN-related QoL and general QoL among advanced LC patients receiving platinum-based chemotherapy.

\section{Methods}

\section{Design and sample selection}

A descriptive cross-sectional study was conducted with a convenience sample from the thoracic oncology inpatient wards of a medical center in northern Taiwan. Data were collected from September 2017 through June 2019. The inclusion criteria were: (1) diagnosis of stage III B or IV LC; (2) receiving platinum-based chemotherapy with cisplatin or carboplatin regimens; (3) receiving at least four cycles of chemotherapy; (4) agreement to participate in the study after explanation of its purposes and procedures; and (5) aged 20 years or older. Patients were not eligible if they had a mental disorder, hypothyroidism, alcoholism, vitamin B1 or B12 insufficiency, discontinuation of scheduled treatment more than 2 months since prior treatment cycles, other comorbid conditions potentially causing CINP (diabetes, thyroid disease, or preexisting neuropathy), or a physical performance less than 60 on the Karnofsky Performance Status Scale (KPS) [21].

The chemotherapy treatment protocol for unresectable advanced LC is a platinum-based regimen of cisplatin or carboplatin given at $75 \mathrm{mg} / \mathrm{m}^{2}$ every 3 weeks for 4 to 6 cycles [22].

\section{Ethical considerations}

Ethical approval was obtained from the Institutional Review Board of the study institution (Number: 201701101B0). The study was conducted in accordance with the Declaration of Helsinki, and written informed consent was obtained from all participants after the study goals and procedures were explained to each in detail.

\section{Data collection}

LC patients who met the inclusion criteria were contacted by a research nurse. Participants filled out the structured questionnaires by self-report in the wards; when necessary, the research nurse read each item of the questionnaire, which took around 10-15 minutes.

\section{Measures}




\section{European Organization for Research and Treatment of Cancer quality of life questionnaire-chemotherapy-induced peripheral neuropathy 20}

CIPN was assessed using the European Organization for Research and Treatment of Cancer quality of life questionnaire-chemotherapy-induced peripheral neuropathy 20 (EORTC QLQ-CIPN20) [23]. The 20-item scale includes three subscales: sensory (9 items), motor (8 items), and autonomic (3 items). Each item is scored from 1 (not at all) to 4 (very much). The summed scores of each subscale and the overall CIPN scale are converted into standardized scores ranging from 0 to 100 , with higher scores representing more CIPN-related symptom distress. The scale was translated into Chinese, and previous cancer-related studies reported satisfactory psychometric properties for the EORTC QLQ-CIPN20 [14,17]. The EORTC QLQ-CIPN20 has been demonstrated to be reliable in a cancer-related study [24]. The Cronbach's a for this study was 0.88 .

\section{Hospital Anxiety and Depression Scale Depression Subscale}

Depression was assessed using the Hospital Anxiety and Depression Scale (HADS) Depression Subscale [25]. Each of the 7 items in the HADS Depression Subscale was scored from 0 (not at all) to 3 (always) and the total score ranges from 0 to 21 , with a higher score indicating greater depression. Scores of 0 to 7 indicate the absence of depression, scores of 8 to 10 indicate borderline depression, and scores of 11 to 21 indicate clinical depression [25]. The scale was translated into Chinese, and a previous cancer-related study reported satisfactory psychometric properties for the HADS [26]. Cronbach's alpha for the HADSDepression Subscale in the present study was 0.88 .

\section{Functional Assessment of Cancer Therapy /Gynecologic Oncology Group-Neurotoxicity subscale}

The CIPN-related QoL was assessed using the Functional Assessment of Cancer Therapy /Gynecologic Oncology Group-Neurotoxicity subscale (FACT/GOG-Ntx) [29]. The instrument consists of 11 items, with responses scored on a Likert scale from 0 (not at all) to 4 (very much), The summed scores of each item are reverted into standardized scores ranging from 0 to 44, with a higher score indicating a lower level of neurological toxicity and less effect on QoL. Satisfactory psychometric properties were reported in a previous study [29]. Cronbach's alpha for the FACT/GOG-Ntx was 0.90.

\section{Functional Assessment of Cancer Therapy-Lung}

The Functional Assessment of Cancer Therapy-Lung (FACT-L) was used to assess general QoL in patients with LC [27]. The 27 item FACT-L contains 5 domains: physical well-being (PWB) (7 items), social/family well-being (SWB) (7 items), emotional well-being (EWB) (6 items), and functional well-being (FWB) (7 items) [27]. Each item is scored on a scale of 0 to 4, with a higher score indicating a better QoL. 
The FACT- $L$ has been demonstrated to be reliable in a cancer-related study [28]. In the present study, the Cronbach's a was 0.88 .

\section{The National Cancer Institute Common Terminology Criteria for Adverse Events 4.03v}

The US National Cancer Institute Common Terminology Criteria for Adverse Events 4.03v (NCI-CTCAE) is widely used in oncology care as the standard classification and severity grading scale for adverse events in cancer therapy clinical trials and other oncology settings [30]. Severity of peripheral motor neuropathy or peripheral sensory impairment is assessed in 5 grades, ranging from 0 to 5: Grade 1, Asymptomatic, clinical or diagnostic observations only; intervention not indicated/ loss of deep tendon reflexes or paresthesia; Grade 2, Moderate symptoms; limiting instrumental activities of daily living (ADL); Grade 3, Severe symptoms; limiting self-care ADL; assistive device indicated; Grade 4, Life-threatening consequences; urgent intervention indicated; and Grade 5, Death [30]. The inter-rater reliability for this study was 0.99 between the research nurse and the oncologist who provided training to the research nurse.

\section{Karnofsky Performance Status Scale}

The KPS scale, used to assess a patient's performance status, ranges from $100 \%$ (normal function) to $0 \%$ (death) [21]. The KPS has been used in clinical cancer studies to assess cancer patients' level of physical function [31,32]. An inter-observer reliability coefficient of 0.98 was reported in the present study.

\section{Demographic and clinical characteristics form}

Demographic data (age, gender, occupation, marital status, education level, and religion) and characteristics of the cancer and treatment (histology type, cancer stage, number of chemotherapy cycles, chemotherapy modalities, total chemotherapy dose, time since diagnosis, and time since the completion of previous chemotherapy) were extracted from the medical record.

\section{Statistical methods}

SPSS, version 26.0 for Windows (IBM Corp., Armonk, NY, USA) was used to analyze the data. Descriptive statistics (frequency distribution, percentage, means, standard deviation errors [SE]) were used to analyze the demographic and clinical characteristics; and the levels of CIPN, depression, CIPN-related QoL, and general QoL. Multiple stepwise regression was used to identify factors associated with CIPN-related QoL and general QoL. The independent variables included marital status, number of chemotherapy cycles, cumulative chemotherapy dose, the EORTC QLQ-CIPN20 scores (CIPN-sensory score, CIPN-motor score, CIPN-autonomic score), and depression.

\section{Results}

\section{Demographic and clinical characteristics}


Of 100 eligible patients approached, 7 declined to participate because they had no time or interest, for a total of 93 patients in the study, $93.0 \%$ of all patients approached. Patients' average age was $59.24 \pm$ 1.20 years. The majority were male $(n=54,58.1 \%)$, unemployed $(n=66,71.0 \%)$, married $(n=65,69.9 \%)$, had a junior high school education or less $(n=48,51.7 \%)$, and held Buddhist/Taoist religious beliefs $(n=$ $62,66.7 \%$ ). A majority of patients were diagnosed with non-small cell lung cancer ( $n=74,79.6 \%)$ and stage IV disease $(n=76,81.7 \%)$. The average number of chemotherapy cycles was 5.53 ; most patients received four cycles of chemotherapy $(n=45,48.4 \%)$; the most common regimen was cisplatin $(n=70$, $75.3 \%$ ); the mean total platinum dose was $682.94 \mathrm{mg}$ ( $\mathrm{SE}=49.57$, range: 121 to $2756 \mathrm{mg}$ ); and all patients had satisfactory KPS scores (60-100). CIPN assessed using the NCI-CTCAE reported that a total of $53.8 \%(n=50)$ of the study subjects had CIPN-sensory impairment with toxicity grade I $(36.6 \%, n=34)$ or grade II $(17.2 \%, n=16)$, and a total of $47.3 \%(n=44)$ had CIPN-motor impairment with toxicity grade I $(32.3 \%, n=30)$ or grade II $(15.0 \%, n=14)$. The rest of the patients reported no CIPN-sensory $(46.2 \%, n=$ 43) or CIPN-motor $(52.7 \%, n=49)$ impairment. The average time since diagnosis was 10.67 months and the average time since the completion of previous chemotherapy was 4.28 weeks (Table 1 ). 
Table 1

Demographic and clinical characteristics of patients $(N=93)$

\begin{tabular}{|c|c|c|c|}
\hline Variable & $\begin{array}{l}\text { Number } \\
\text { (\%) }\end{array}$ & Mean (SE) & Range \\
\hline Age (years) & & $59.24(1.20)$ & $27-89$ \\
\hline \multicolumn{4}{|l|}{ Sex } \\
\hline Male & \multicolumn{3}{|l|}{$54(58.1)$} \\
\hline Female & \multicolumn{3}{|l|}{$39(41.9)$} \\
\hline \multicolumn{4}{|l|}{ Occupation } \\
\hline Unemployed & \multicolumn{3}{|l|}{$66(71.0)$} \\
\hline Employed & \multicolumn{3}{|l|}{$27(29.0)$} \\
\hline \multicolumn{4}{|l|}{ Marital status } \\
\hline Unmarried & \multicolumn{3}{|l|}{$28(30.1)$} \\
\hline Married & \multicolumn{3}{|l|}{$65(69.9)$} \\
\hline \multicolumn{4}{|l|}{ Education level } \\
\hline None & \multicolumn{3}{|l|}{$4(4.3)$} \\
\hline Elementary & \multicolumn{3}{|l|}{ 18(19.4) } \\
\hline Junior high & \multicolumn{3}{|l|}{$26(28.0)$} \\
\hline Senior high & \multicolumn{3}{|l|}{$28(30.1)$} \\
\hline College and above & \multicolumn{3}{|l|}{ 17(18.2) } \\
\hline \multicolumn{4}{|l|}{ Religion } \\
\hline None & \multicolumn{3}{|l|}{$27(29.0)$} \\
\hline Buddhism/ Taoism & \multicolumn{3}{|l|}{$62(66.7)$} \\
\hline Christianity/ Catholicism & \multicolumn{3}{|l|}{$4(4.3)$} \\
\hline \multicolumn{4}{|l|}{ Histology type } \\
\hline NSCLC & \multicolumn{3}{|l|}{ 74(79.6) } \\
\hline SCLC & \multicolumn{3}{|l|}{ 19(20.4) } \\
\hline \multicolumn{4}{|c|}{$\begin{array}{l}S D \text {, standard deviation; } R T \text {, radiotherapy; } C T \text {, chemotherapy; } C C R T \text {, combined chemotherapy and } \\
\text { radiotherapy; KPS, Karnof sky performance score }\end{array}$} \\
\hline \multicolumn{4}{|c|}{ CIPN, Chemotherapy-Induced Peripheral Neuropathy } \\
\hline
\end{tabular}




\begin{tabular}{|c|c|c|c|}
\hline Variable & $\begin{array}{l}\text { Number } \\
(\%)\end{array}$ & Mean (SE) & Range \\
\hline \multicolumn{4}{|l|}{ Cancer stage } \\
\hline$\bigotimes \mathrm{B}$ & 17(18.3) & & \\
\hline IV & 76(81.7) & & \\
\hline Number of chemotherapy cycle & $5.53(2.75)$ & & $4-22$ \\
\hline 4 & $45(48.4)$ & & \\
\hline 5 & $24(25.8)$ & & \\
\hline$\geq 6$ & $24(25.8)$ & & \\
\hline \multicolumn{4}{|l|}{ Chemotherapy modalities } \\
\hline Cisplatin & 70(75.3) & & \\
\hline Carboplatin & $5(5.4)$ & & \\
\hline Cisplatin + docetaxel & 15(16.1) & & \\
\hline Carboplatin + docetaxel & $3(3.2)$ & & \\
\hline Chemotherapy, total dose, mg & & 682.94(49.57) & $\begin{array}{l}121- \\
2756\end{array}$ \\
\hline \multicolumn{4}{|c|}{ Severity of CIPN-sensory impairment } \\
\hline No CIPN impairment & $43(46.2)$ & & \\
\hline \multicolumn{4}{|l|}{ NCl-CTCAE grade ${ }^{a}$} \\
\hline I & $34(36.6)$ & & \\
\hline II & 16(17.2) & & \\
\hline III & $0(0)$ & & \\
\hline \multicolumn{4}{|c|}{ Severity of CIPN-motor impairment } \\
\hline No CIPN impairment & 49(52.7) & & \\
\hline \multicolumn{4}{|l|}{ NCl-CTCAE grade ${ }^{a}$} \\
\hline I & $30(32.3)$ & & \\
\hline
\end{tabular}

$S D$, standard deviation; $R T$, radiotherapy; $C T$, chemotherapy; $C C R T$, combined chemotherapy and radiotherapy; KPS, Karnofsky performance score

CIPN, Chemotherapy-Induced Peripheral Neuropathy

NCI-CTCAE- The Common Terminology Criteria for Adverse Events (CTCAE) 4.03v. 


\begin{tabular}{|c|c|c|c|}
\hline Variable & $\begin{array}{l}\text { Number } \\
(\%)\end{array}$ & Mean (SE) & Range \\
\hline II & 14(15.0) & & \\
\hline III & $0(0)$ & & \\
\hline KPS score (level) & & $85.74(0.45)$ & $70-90$ \\
\hline 90 to 100 & 10(10.8) & & \\
\hline 80 to 90 & $61(65.6)$ & & \\
\hline 70 to 80 & 16(17.2) & & \\
\hline 60 to 70 & $6(6.5)$ & & \\
\hline Time since diagnosis (months) & & $10.67(1.46)$ & $2-84$ \\
\hline $\begin{array}{l}\text { Time since the completion of previous chemotherapy } \\
\text { (weeks) }\end{array}$ & & $4.28(0.21)$ & $1-11$ \\
\hline \multicolumn{4}{|c|}{$\begin{array}{l}S D \text {, standard deviation; } R T \text {, radiotherapy; } C T \text {, chemotherapy; } C C R T \text {, combined chemotherapy and } \\
\text { radiotherapy; KPS, Karnofsky performance score }\end{array}$} \\
\hline \multicolumn{4}{|l|}{ CIPN, Chemotherapy-Induced Peripheral Neuropathy } \\
\hline NCI-CTCAE- The Common Terminc & & $4.03 \mathrm{v}$. & \\
\hline
\end{tabular}

\section{Top chemotherapy-induced peripheral neuropathy (CIPN) symptoms}

The highest-scoring CIPN symptoms in descending ranking were: "did you have difficulty getting or maintaining an erection?" (mean $=56.02, \mathrm{SE}=4.33$ ); "did you have difficulty climbing stairs or getting up out of a chair because of weakness in your legs?" (mean $=40.59, \mathrm{SE}=2.02$ ); and "did you have blurred vision?" (mean $=37.63, \mathrm{SE}=1.56)($ Table 2$)$. 
Table 2

Top ten CIPN measurement by EORTC QLQ-CIPN $20(N=93)$

\begin{tabular}{|c|c|c|}
\hline Variable & Domain & Mean (SE) \\
\hline 20. Did you have difficulty getting or maintaining an erection? & Autonomic & $56.02(4.33)$ \\
\hline $\begin{array}{l}\text { 15. Did you have difficulty climbing stairs or getting up out of a chair } \\
\text { because of weakness in your legs? }\end{array}$ & Motor & $40.59(2.02)$ \\
\hline 17. Did you have blurred vision? & Autonomic & $37.63(1.56)$ \\
\hline 16. Were you dizzy when standing up from a sitting or lying position? & Autonomic & $36.56(1.60)$ \\
\hline 4. Did you have numbness in your toes or feet? & Sensory & $34.95(1.84)$ \\
\hline 3. Did you have numbness in your fingers or hands? & Sensory & $34.14(1.66)$ \\
\hline 11. Did you have a problem holding a pen, which made writing difficult? & Motor & $30.65(1.22)$ \\
\hline $\begin{array}{l}\text { 9. Did you have problems standing or walking because of difficulty } \\
\text { feeling the ground under your feet? }\end{array}$ & Sensory & $30.11(1.24)$ \\
\hline 18. Did you have difficulty hearing? & Sensory & $30.11(1.30)$ \\
\hline $\begin{array}{l}\text { 12. Did you have difficulty manipulating small objects with your fingers } \\
\text { (for example, fastening small buttons)? }\end{array}$ & Motor & 29.30(1.30) \\
\hline \multicolumn{3}{|c|}{$\begin{array}{l}\text { EORTC QLQ-CIPN 20, European Organization for Research and Treatment of Cancer quality of life } \\
\text { questionnaire-chemotherapy-induced peripheral neuropathy } 20 \text {, each item rated on a scale of } 0-4 \\
\text { (not at all }=1 \text {, a little }=2 \text {, quite a bit }=3 \text {, and very much }=4 \text { ), theoretical scoring range } 0-100 \text {. }\end{array}$} \\
\hline
\end{tabular}

The overall mean CIPN score was $31.56(\mathrm{SE}=0.84)$. Mean scores for the subscales were: sensory, 29.15 ( $\mathrm{SE}=0.57$ ); motor, 31.83 ( $\mathrm{SE}=0.93$ ); and autonomic, 33.81 ( $\mathrm{SE}=1.45$ ). The mean score for depression was $6.67(S E=0.49)$. According to the HADS classification, 23.7\% $(n=22)$ and $17.2 \%(n=16)$ of patients were classified as having clinical depression and borderline depression, respectively. The mean score for CIPN-related QoL was 40.44 (SE = 0.57). The mean score for overall general QoL was $78.08(S E=1.68)$. Mean scores for the subscales were: PWB, 20.79 (SE = 0.59); SFWB, 20.31 (SE = 0.43); EWB, 19.01 (SD = 0.50); and FWB, $17.97(\mathrm{SE}=0.68)($ Table 3).

Table 3

Scores for CIPN, depression, CIPN-related QoL, and general QoL $(N=93)$ 


\begin{tabular}{|c|c|c|c|c|}
\hline Variable & Mean/N & $\mathrm{SE} / \%$ & Range & $\begin{array}{l}\text { Theoretical } \\
\text { scoring } \\
\text { range }\end{array}$ \\
\hline CIPN (EORTC QLQ-CIPN 20) & 31.56 & 0.84 & $\begin{array}{l}0- \\
38.89\end{array}$ & $0-100$ \\
\hline - Sensory & 29.15 & 0.57 & $\begin{array}{l}0- \\
38.89\end{array}$ & $0-100$ \\
\hline - Motor & 31.83 & 0.93 & $\begin{array}{l}0- \\
32.14\end{array}$ & $0-100$ \\
\hline - Autonomic & 33.81 & 1.45 & $\begin{array}{l}0- \\
62.50\end{array}$ & $0-100$ \\
\hline Depression (HADS-depression subscale) & 6.67 & 0.49 & $0-17$ & $0-21$ \\
\hline - Noncases & 55 & 59.10 & & \\
\hline - Borderline Cases & 16 & 17.20 & & \\
\hline - Clinical Cases & 22 & 23.70 & & \\
\hline CIPN-related QoL (Ntx subscale) & 40.44 & 0.57 & $\begin{array}{l}11- \\
44\end{array}$ & $0-44$ \\
\hline $\begin{array}{l}\text { - I have trouble feeling the shape of small objects when } \\
\text { they are in my hand }\end{array}$ & 3.88 & 0.46 & $1-4$ & $0-4$ \\
\hline - I have trouble hearing & 3.81 & 0.56 & $1-4$ & $0-4$ \\
\hline - I have trouble buttoning buttons & 3.80 & 0.58 & $1-4$ & $0-4$ \\
\hline - I have joint pain or muscle cramps & 3.76 & 0.76 & $0-4$ & $0-4$ \\
\hline - I have trouble walking & 3.75 & 0.72 & $0-4$ & $0-4$ \\
\hline General QoL (FACT-G) & 78.08 & 1.68 & $\begin{array}{l}26- \\
102\end{array}$ & $0-108$ \\
\hline - Physical well-being (PWB) & 20.79 & 0.59 & $5-28$ & $0-28$ \\
\hline - Social/family well-being (SFWB) & 20.31 & 0.43 & $0-24$ & $0-28$ \\
\hline - Emotional well-being (EWB) & 19.01 & 0.50 & $1-24$ & $0-24$ \\
\hline - Functional well-being (FWB) & 17.97 & 0.68 & $3-28$ & $0-28$ \\
\hline \multicolumn{5}{|c|}{$\begin{array}{l}\text { EORTC QLQ-CIPN 20, European Organization for Research and Treatment of Cancer quality of life } \\
\text { questionnaire-chemotherapy-induced peripheral neuropathy } 20 \text {, theoretical scoring range } 0- \\
100 ; \text { HADS-depression subscale, Hospital Anxiety and Depression Scale-depression subscale, } \\
\text { theoretical scoring range: } 0-21 \text {; Ntx subscale, The Functional Assessment of Cancer Therapy- } \\
\text { Neurotoxicity subscale, theoretical scoring range: } 0-44 ; \text { FACT-G, The Functional Assessment of } \\
\text { Cancer Therapy-General, theoretical scoring range: } 0-108 \text {. }\end{array}$} \\
\hline
\end{tabular}

Factors associated with CIPN-related QOL and general QoL 
Multiple regression analysis identified the factors that were significantly and independently associated with CIPN-related QoL and general QoL. Patients who had greater CIPN-sensory scores $(\beta=-0.658)$ and CIPN-motor scores $(\beta=-0.215)$ were more likely to have worse CIPN-related QoL. These two factors explained $64.5 \%$ of the total variance in CIPN-related QoL. Patients who had a higher level of depression $(\beta=-2.768)$, who had higher CIPN-sensory scores $(\beta=-0.602)$, and who received a greater cumulative dose of chemotherapy $(\beta=0.006)$ were more likely to have worse general QoL. These three factors explained $57.6 \%$ of the total variance in general QoL (Table 4).

Table 4

Factors significantly associated with CIPN-related QoL and general QoL based on multiple regression analysis $(N=93)$

\begin{tabular}{|c|c|c|c|c|c|c|c|}
\hline \multirow{2}{*}{$\begin{array}{l}\text { Domains of } \\
\text { QoL }\end{array}$} & \multirow[t]{2}{*}{ Predictive variable } & \multirow{2}{*}{$\begin{array}{l}\text { Adjusted } \\
\mathrm{R}^{2}\end{array}$} & \multirow[t]{2}{*}{ Beta } & \multirow[t]{2}{*}{$F$} & \multirow[t]{2}{*}{ p } & \multicolumn{2}{|l|}{$95 \% \mathrm{Cl}$} \\
\hline & & & & & & Lower & Upper \\
\hline \multirow{3}{*}{$\begin{array}{l}\text { CIPN-related } \\
\text { QoL (Ntx } \\
\text { subscale) }\end{array}$} & CIPN-sensory & 0.645 & -0.658 & 84.754 & 0.001 & -0.798 & 45.086 \\
\hline & CIPN-motor & & -0.215 & & 0.001 & -0.329 & -0.517 \\
\hline & Constant & & 44.193 & & 0.001 & 43.301 & -0.101 \\
\hline \multirow{4}{*}{$\begin{array}{l}\text { General QoL } \\
\text { (FACT-G) }\end{array}$} & Depression & 0.576 & -2.768 & 42.707 & 0.001 & -3.315 & -2.221 \\
\hline & CIPN-sensory & & -0.602 & & 0.014 & -1.077 & -0.127 \\
\hline & $\begin{array}{l}\text { Cumulative dose } \\
\text { of chemotherapy } \\
\text { therapy }\end{array}$ & & 0.006 & & 0.039 & 0.001 & 0.011 \\
\hline & Constant & & 136.084 & & 0.001 & 130.289 & 141.880 \\
\hline \multicolumn{8}{|c|}{ FACT/GOG-Ntx, The Functional Assessment of Cancer Therapy-Neurotoxicity subscale } \\
\hline \multicolumn{8}{|c|}{ FACT-G, The Functional Assessment of Cancer Therapy-General } \\
\hline \multicolumn{8}{|c|}{$\begin{array}{l}\text { Input independent variable: covariates included marital status (not married vs. married), number of } \\
\text { chemotherapy cycles (continuous score), cumulative dose of chemotherapy therapy (continuous } \\
\text { score), CIPN-sensory (continuous score), CIPN-motor (continuous score), CIPN- autonomic } \\
\text { (continuous score), and depression (continuous score). }\end{array}$} \\
\hline
\end{tabular}

\section{Discussion}

In this study, among patients with advanced LC who received platinum-based regimens, the prevalence of grade $0, I, I I$, and III CIPN-sensory adverse events were $46.2 \%(n=43), 36.6 \%(n=34), 17.2 \%(n=16)$, and $0 \%(n=0)$, respectively, and the prevalence of grade $0, I, I I$, and III CIPN-motor adverse events were $52.7 \%$ $(n=49), 32.3 \%(n=30), 15.0 \%(n=14)$, and $0 \%(n=0)$, respectively. Kautio et al. [33] found that, in patients who received vinca alkaloid, taxane, or platina derivative regimens, $0 \%, 21 \%, 42 \%$, and $37 \%$ of 
patients reported a prevalence of grade $0, \mathrm{I}, \mathrm{II}$, and III sensory CIPN adverse events, respectively, and $52 \%$, $31 \%, 16 \%$, and $1 \%$ of patients reported the prevalence of grade $0, \mathrm{I}, \mathrm{II}$, and III motor CIPN adverse events, respectively. The reduced level of neuropathy may result from the fact that patients in Kautio et al. [33] had received 1-3 cycles of treatment, while our subjects had received at least 4 cycles of chemotherapy; indeed, more than half $(51.6 \%)$ had received 5 or more cycles of treatment, and were still continuing treatment. CIPN symptoms were present within a few days after starting therapy and lasted for several months after beginning treatment. Healthcare providers should seek to detect CIPN early and continue assessment of CIPN as patients continue their chemotherapy.

Our results showed that the average CIPN-related QoL score of patients with advanced LC was 40.44 $(S E=0.57)$. The level of CIPN-related QoL among subjects in this study was lower than that reported in another recent study [34]. This difference may be due to the different cycles of chemotherapy during which patients were assessed. Patients in our study received an average of 5.53 cycles of chemotherapy and had not yet completed all cycles of chemotherapy, while patients in the study of Ajewole et al. [34] were enrolled within 2 weeks of the first chemotherapy of cycle 1 and followed for 12 weeks after enrollment. These findings may reflect that the impact of CIPN on QoL increases over time. CIPN in advanced LC patients treated with platinum-based chemotherapy may impact their ability to perform selfcare, independently complete ADLs, and return to work, as well as their level of physical activity. Healthcare providers should be aware of patients' reports of outcomes related to CIPN and provide care for their needs.

The most highly rated CIPN items for patients in the present study were: difficulty getting/maintaining an erection, difficulty climbing stairs/rising from a chair, blurred vision, dizziness when standing up from a sitting/lying position, and numbness in the toes/feet. These findings agree with those of previous studies of cancer patients treated with CIPN-related regimens, which indicated that tingling or numbness in the fingers/hands, toes/feet were most the common CIPN-related symptoms, and may limit ADLs and diminish QoL $[35,36]$. In the present study, difficulty getting / maintaining an erection was the most common problem. Male patients may be embarrassed to discuss their perceptions and feelings about sexual dysfunction. Healthcare providers should therefore actively evaluate each patient's concerns about changes in sexual function and encourage male patients in particular to express their feelings.

Results of the present study indicated that patients who had a higher level of depression and who had more severe CIPN-sensory scores were more likely to have worse overall QoL. These results are consistent with those of previous studies [37], which reported that CIPN [36] and depression [37] lead to restrictions in ADLs [37] and decreases in mobility and independency [38] in cancer patients treated with platinum-based antineoplastic agents. Healthcare professionals should evaluate neurological function and provide information on nutritional supplements, aerobic exercise, and balance training that may stimulate peripheral neurological function and enhance daily function, to help patients cope with the adverse effects of chemotherapy.

\section{Limitations}


This study had several limitations. First, the present study examined patients with advanced LC who received at least 4 chemotherapy cycles, and although such problems may develop as early as 1-2 weeks after initiating treatment, CIPN following chemotherapy cycles is part of a dynamic process that changes over time. Longitudinal studies are needed, with long-term follow up of patients from the time they undergo treatment through the post-treatment period. Second, we did not consider the effect of nutritional supplements (glutathione, glutamine, vitamin E, or B complex) or dietary supplements (vitamins, minerals, proteins, or amino acids) as factors in CIPN, although such factors may affect outcomes. Thus, future studies should extend their analysis to include the use of nutritional supplements. Finally, patients' initial (pre-treatment) peripheral neurological function and lifestyle, variables not studied here, may have affected the evaluation of CIPN. Further studies are needed to determine the correlation between initial peripheral neurological function, lifestyle, and CIPN.

\section{Conclusions}

We found that $53.8 \%$ and $47.3 \%$ of advanced LC patients receiving platinum-based chemotherapy reported CIPN-sensory impairment and CIPN-motor impairment, respectively. Patients who had a higher level of depression, greater CIPN-sensory impairment, and those receiving a higher cumulative dose of chemotherapy were more likely to have a worse overall general QoL. Patients who had greater CIPNsensory and CIPN-motor impairment were more likely to have worse CIPN-related QoL. CIPN-sensory impairment was the most important factor associated with overall general QoL and CIPN-related QoL.

\section{Clinical implications}

The results of this study provide a reference for clinical assessment of CIPN and the factors associated with CIPN-related QoL and general QoL in patients with advanced LC receiving platinum-based chemotherapy. Based on the results of the current study, these patients need a holistic approach to help them maximize their QoL, including health education, dietary guidance, nutritional supplements, aerobic exercise, and balance training.

\section{Declarations}

\section{Funding}

Chang Gung Memorial Hospital, Grant/Award Number: CMRPG3G1321, CMRPF1H0131, CMRPF1K0021, CMRPF1K0022, CMRPF3K0011, NMRPF3K0052, NMRPF3K0053, NMRPF3K0061, NMRPF3K0062, NMRPF3J0181 and NMRPF3J0182. Chang Gung University of Science and Technology, Grant/Award Number: ZRRPF3H0061. Ministry of Science and Technology (MOST), Grant/Award Number: MOST 1052628-B-255 -001 -MY3 and MOST 108-2314-B-255-006-MY3.

\section{Conflicts of interest}

The authors declare that they have no conflict of interest. 


\section{Ethics approval}

All procedures performed in studies involving human participants were in accordance with the ethical standards of the University of Wisconsin Health Sciences IRB (Number: 201701101B0) and with the 1964 Helsinki Declaration and its later amendments or comparable ethical standards.

\section{Consent to participate and consent for publication}

Informed consent was obtained from all individual participants included in the study.

\section{Availability of data and material}

The data that support the findings of this study are available from the corresponding author. Restrictions apply to the availability of these data, which were used under license for this study. Data are available from the authors with the permission of Chang Gung Memorial Hospital Research Program, Chang Gung University of Science and Technology, and Ministry of Science and Technology (MOST) in Taiwan.

\section{Authors' contribution}

Conceptualization, H.-W.H. and S.-C.C.; methodology, S.-C.C.; software, H.-W.H.; validation, H.-W.H., C.-Y.L., H.-F.C., and S.-C.C.; formal analysis, H.-W.H. and S.-C.C.; investigation, H.-W.H., C.-Y.L., and S.-C.C.; resources, S.-C.C.; data curation, C.-Y.L.; writing-original draft preparation, C.-Y.L. and S.-C.C.; writingreview and editing; visualization, H.-W.H., C.-Y.L., H.-F.C., and S.-C.C.; supervision, S.-C.C.; project administration, H.-W.H. and S.-C.C. All authors have read and agreed to the published version of the manuscript.

\section{References}

1. World Health Organization (2020) WHO report on cancer: setting priorities, investing wisely and providing care for all. Geneva: World Health Organization. License: CC BY-NC-SA 3.0 IGO.

2. Taiwan Cancer Registry (2016) 2016 annual report. http://crs.cph.ntu.edu.tw/. Accessed January 4, 2021

3. Cavaletti G, Marmiroli P (2015) Chemotherapy-induced peripheral neurotoxicity. Curr Opin Neurol 2015;28:500-507. https://doi.org/1097/WC0.0000000000000234

4. Banach M, Juranek JK, Zygulska AL (2016) Chemotherapy-induced neuropathies-A growing problem for patients and health care providers. Brain Behav 7:e00558. https://doi.org/1002/brb3.558

5. Seretny M, Currie GL, Sena ES, Ramnarine S, Grant R, MacLeod MR, Colvin LA, Fallon M (2014) Incidence, prevalence, and predictors of chemotherapy-induced peripheral neuropathy: a systematic review and meta-analysis. Pain 155:2461-2470. https://doi.org/1016/j.pain.2014.09.020 
6. Visovsky C, Collins M, Abbott L, Aschenbrenner J, Hart C (2007) Putting evidence into practice: Evidence-based interventions for chemotherapy-induced peripheral neuropathy. Clin J Oncol Nurs 11:901-913. https://doi.org/1188/07. CJON.901-913

7. Miltenburg NC, Boogerd W. Chemotherapy-induced neuropathy: a comprehensive survey. Cancer Treat Rev 2014;40:872-882. https://doi.org/1016/j.ctrv.2014.04.004

8. Driessen CM, de Kleine-Bolt KM, Vingerhoets AJ, Mols F, Vreugdenhil G (2012) Assessing the impact of chemotherapy-induced peripheral neuro-toxicity on the quality of life of cancer patients. Support Care Cancer 20:877- https://doi.org/10.1007/s00520-011-1336-0

9. Nummi A, Järvinen R, Sairanen J, Huotari K (2019) A retrospective study on tolerability and complications of bacillus Calmette-Guérin (BCG) instillations for non-muscle-invasive bladder cancer. Scand J Urol 53:116 - https://doi.org/10.1080/21681805.2019.1609080

10. Bonhof CS, van de Poll-Franse LV, Vissers PAJ, Wasowicz DK, Wegdam JA, Révész D, Vreugdenhil G, Mols F. (2019) Anxiety and depression mediate the association between chemotherapy-induced peripheral neuropathy and fatigue: Results from the population-based PROFILES registry.

Psychooncology 28:1926- https://doi.org/10.1002/pon.5176

11. Salgado TM, Quinn CS, Krumbach EK, Wenceslao I, Gonzalez M, Reed HL, Syverson JG, Etz RS, Vangipuram K, Barker MR, Henry NL, Farris KB, Hertz DL. (2020) Reporting of paclitaxel-induced peripheral neuropathy symptoms to clinicians among women with breast cancer: a qualitative study. Support Care Cancer 28:4163- https://doi.org/10.1007/s00520-019-05254-6

12. Bonhof CS, van de Poll-Franse LV, Wasowicz DK, Beerepoot LV, Vreugdenhil G, Mols F (2020) The course of peripheral neuropathy and its association with health-related quality of life among colorectal cancer patients [published online ahead of print, 2020 Nov 13]. J Cancer Surviv https://doi.org/1007/s11764-020-00923-6

13. Prieto-Callejero B, Rivera F, Fagundo-Rivera J, Romero A, Romero-Martín M, Gómez-Salgado J, RuizFrutos $C$ (2020) Relationship between chemotherapy-induced adverse reactions and health-related quality of life in patients with breast cancer. Medicine (Baltimore) 99:e21695. https://doi.org/1097/MD.0000000000021695

14. Hsu SY, Huang WS, Lee SH, Chu TP, Lin YC, Lu CH, Beaton RD, Jane SW (2019) Incidence, severity, longitudinal trends and predictors of acute and chronic oxaliplatin-induced peripheral neuropathy in Taiwanese patients with colorectal cancer. Eur J Cancer Care (Engl) 28:e12976. https://doi.org/1111/ecc.12976

15. Hsu HT, Wu LM, Lin PC, Juan CH, Huang YY, Chou PL, Chen JL (2020) Emotional distress and quality of life during folinic acid, fluorouracil, and oxaliplatin in colorectal cancer patients with and without chemotherapy-induced peripheral neuropathy: a cross-sectional study. Medicine (Baltimore) 99:e19029. https://doi.org/1097/MD.0000000000019029

16. Lu LC, Tsay SL, Chang SY, Chen CM, Liu CY (2019) Daily activity, mood, and quality of life in colorectal cancer patients with chemotherapy-induced peripheral neuropathy: a mediation effect analysis. Cancer Med 8:963- https://doi.org/ 10.1002/cam4.1976 
17. Wang YJ, Chan YN, Jheng YW, Wu CJ, Lin MW, Tseng LM, Tsai YF, Liu LC (2020) Chemotherapyinduced peripheral neuropathy in newly diagnosed breast cancer survivors treated with taxane: a prospective longitudinal study [published online ahead of print, 2020 Oct 6]. Support Care Cancer https://doi.org/1007/s00520-020-05796-0

18. Bridges CM, Smith EM (2014) What about Alice? Peripheral neuropathy from taxane-containing treatment for advanced nonsmall cell lung cancer. Support Care Cancer 22:2581-25 https://doi.org/10.1007/s00520-014-2317-x

19. Hirsh V, Okamoto I, Hon JK, Page RD, Orsini J, Sakai H, Zhang H, Renschler MF, Socinski MA (2014) Patient-reported neuropathy and taxane-associated symptoms in a phase 3 trial of nab-paclitaxel plus carboplatin versus solvent-based paclitaxel plus carboplatin for advanced non-small-cell lung cancer. J Thorac Oncol 9:83- https://doi.org/10.1097/JT0.0000000000000011

20. Kawakami K, Tunoda T, Takiguchi T, Shibata K, Ohtani T, Kizu J, Nishio M, Horai T, Hama T, Taguchi K. (2012) Factors exacerbating peripheral neuropathy induced by paclitaxel plus carboplatin in nonsmall cell lung cancer. Oncol Res 20:179- https://doi.org/10.3727/096504012x13522227232192

21. Karnofsky DA, Abelmann WH, Craver LF, Burchenal JH (1948) The use of the nitrogen mustards in the palliative treatment of carcinoma with particular reference to bronchogenic. Cancer 1:634-

22. Ettinger DS, Wood DE, Aggarwal C et al (2019). NCCN Guidelines Insights: Non-small cell lung cancer, Version 1.2020. J National Compr Cancer Netw 17:1464-https://doi.org/10.6004/jnccn.2019.0059

23. Postma TJ, Aaronson NK, Heimans JJ et al (2005) The development of an EORTC quality of life questionnaire to assess chemotherapy induced peripheral neuropathy: The QLQ-CIPN20. Eur J Cancer 41:1135- https://doi.org/10.1016/j.ejca.2005.02.012

24. Lavoie Smith EM, Barton DL, Qin R, Steen PD, Aaronson NK, Loprinzi CL (2013) Assessing patientreported peripheral neuropathy: the reliability and validity of the European Organization for Research and Treatment of Cancer QLQ-CIPN20 Questionnaire. Qual Life Res 22:2787-2799. https://doi.org/10.1007/s11136-013-0379-8

25. Zigmond AS, Snaith RP. (1983) The hospital anxiety and depression scale. Acta Psychiatr Scand 67:361-3

26. Chang YL, Huang BS, Hung TM, Lin CY, Chen SC (2019) Factors influencing body image in posttreatment oral cavity cancer patients. Psychooncology 28:1127https://doi.org/10.1002/pon.5067

27. Cella DF, Bonomi AE, Lloyd SR, Tulsky DS, Kaplan E, Bonomi P (1995) Reliability and validity of the Functional Assessment of Cancer Therapy-Lung (FACT-L) quality of life instrument. Lung Cancer 12:199- https://doi.org/10.1016/0169-5002(95)00450-f

28. Chang WP, Lin YK, Lin CC (2019) Psychometric evaluation of the Taiwanese version of the functional assessment of cancer therapy: a questionnaire for patients with lung cancer. Int J Qual Health Care 31:513- https://doi.org/10.1093/intqhc/mzy201

29. Calhoun EA, Welshman EE, Chang CH, Lurain JR, Fishman DA, Hunt TL, Cella D Psychometric evaluation of the Functional Assessment of Cancer Therapy/Gynecologic Oncology Group- 
Neurotoxicity(Fact/GOG-Ntx) questionnaire for patients receiving systemic chemotherapy. Int J Gynecol Cancer 13:741-

30. National Cancer Institute (2010) Common Terminology Criteria for Adverse Events (CTCAE), Version 4.0, Available from: http://

https://evs.nci.nih.gov/ftp1/CTCAE/CTCAE_4.03/Archive/CTCAE_4.0_2009-05-

29_QuickReference_8.5x11.pdf Accessed January 14, 2021

31. Chiang TY, Hsu HC, Jane SW, Chen SC (2020) EGFRI-associated health-related quality of life by severity of skin toxicity in metastatic colorectal cancer patients receiving epidermal growth factor receptor inhibitor target therapy. Support Care Cancer 28:4771- https://doi.org/10.1007/s00520020-05321-3

32. Hsu YH, Shen WC, Wang CH, Lin YF, Chen SC (2019) Hand-foot syndrome and its impact on daily activities in breast cancer patients receiving docetaxel-based chemotherapy. Eur $\mathrm{J}$ Oncol Nurs 43:101670. https://doi.org/1016/j.ejon.2019.09.011

33. Kautio AL, Haanpää M, Kautiainen H, Kalso E, Saarto T. (2011) Burden of chemotherapy-induced neuropathy-a cross-sectional study. Support Care Cancer 19:1991- https://doi.org/10.1007/s00520010-1043-2

34. Ajewole VB, Cox JE, Swan JT, Chikermane SG, Lamoth B, Iso T, Okolo LO, Ford CL, Schneider AM, Hobaugh EC, Baker KR (2020) Incidence of chemotherapy-induced peripheral neuropathy within 12 weeks of starting neurotoxic chemotherapy for multiple myeloma or lymphoma: a prospective, single-center, observational study. Support Care Cancer 28:1901- https://doi.org/10.1007/s00520019-05006-6

35. Kieffer JM, Postma TJ, van de Poll-Franse L, Mols F, Heimans JJ, Cavaletti G, Aaronson NK, ClPeriNomS Group (2017) Evaluation of the psychometric properties of the EORTC chemotherapyinduced peripheral neuropathy questionnaire (QLQ-CIPN20). Qual Life Res 26:2999https://doi.org/10.1007/s11136-017-1626-1

36. Smith EML, Zanville N, Kanzawa-Lee G, Donohoe C, Bridges C, Loprinzi C, Le-Rademacher J, Yang JJ. (2019) Rasch model-based testing of the European Organisation for Research and Treatment of Cancer (EORTC) Quality of Life Questionnaire-Chemotherapy-Induced Peripheral Neuropathy (QLQCIPN20) using Alliance for Clinical Trials in Oncology (Alliance) A151408 study data. Support Care Cancer 27:2599- https://doi.org/10.1007/s00520-018-4553-y

37. Oh PJ, Lee JR, Kim SK, Kim JH. (2020) Changes in chemotherapy-induced peripheral neuropathy, disturbance in activities of daily living, and depression following chemotherapy in patients with colorectal cancer: a prospective study. Eur J Oncol Nurs 44:101676. https://doi.org/1016/j.ejon.2019.101676

38. van Haren F, Steegers M, Thijssen M, van der Wal S, Vissers K, Engels Y. (2020) Qualitative evaluation of the influence of acute oxaliplatin-induced peripheral neuropathy on quality of life and activities of daily life [published online ahead of print, 2020 Dec 10]. Pain Pract https://doi.org/1111/papr.12981 